Original Research Paper

\title{
Exposure to Mercury at Trace Concentrations Leads to Collapse of the Hepato-Nephrocitic System in Two Neotropical Species of Bumblebee
}

\author{
${ }^{1}$ Felipe Lissoni de Andrade Nogueira, ${ }^{1}$ Paulo José Bálsamo, ${ }^{2}$ Monica Jones Costa and ${ }^{1}$ Fábio Camargo Abdalla \\ ${ }^{1}$ Department of Biology, Laboratory of Structural and Functional Biology, Post-graduate Program in Biotechnology and \\ Environmental Biomonitoring Federal University of São Carlos, UFSCar, Campus Sorocaba, Brazil \\ ${ }^{2}$ Department of Biology, Laboratory of Conservative Physiology, Post-graduate Program in Biotechnology and Environmental \\ Biomonitoring Federal University of São Carlos, UFSCar, Campus Sorocaba, Brazil
}

Article history

Received: 29-08-2018

Revised: 06-11-2018

Accepted: 13-12-2018

Corresponding Author: Fábio Camargo Abdalla Department of Biology, Federal University of São Carlos (UFSCar), Campus Sorocaba, State of São Paulo, Brazil Tel +15 15 3229-5986, Fax: +551532296179

E-mail: fabdalla@ufscar.br

\begin{abstract}
This research aimed to investigate the effects of exposure to safe concentrations of mercury on the morpho-physiology of cells of the hepatonephrocitic system of two species of neotropical bees. Workers of the neotropical bumblebee species Bombus morio and B. atratus were exposed to $0.2 \mathrm{ppb}$ mercury for $48 \mathrm{~h}$ by ingestion. Bioassays were performed according some direction of OECD (2017) for bioassays in B. terrestris. The mercury concentration used is allowed for all types of water bodies for the Brazilian Environmental Council standards. The results showed that exposure severely impacted the fat body cells (oenocytes and trophocytes) and pericardial cells, either morphology and HSP70 expression, of both species and may represent a threat for these neotropical bee species. We observed that $B$. atratus is more sensitive to mercury exposure, although the two species have a very close phylogenetic relationship. To the best of our knowledge, this is the first study to compare the expression pattern of HSP70 in the fat body and pericardial cells of neotropical bumblebees under normal and mercury-exposure conditions. Both species expressed the protein in all studied cells under normal and exposed conditions; however, mercury exposure led to overexpression of HSP70 in B. morio workers only, with reduced expression observed in $B$. atratus following exposure. We conclude that $0.2 \mathrm{ppb}$ of mercury severely impacts both species, being B. atratus more susceptible.
\end{abstract}

Keywords: Bombus, Mercury, Pericardial Cells, Fat Body, HSP70

\section{Introduction}

The worldwide decline and loss of several species of bees of the Bombus genus has been recorded annually for the last decade (Gallai et al., 2009; Grixti et al., 2009; Carswell, 2015; Goulson et al., 2015; Woodcock et al., 2016; Rhoades et al., 2016). Populations of Bombus affinis have decreased drastically in the USA and the species is now considered critically endangered by the U.S. Fish and Wildlife Service (2017). In the state of Paraná and in some parts of the states of Santa Catarina, Brazil, the decline and subsequent disappearance of $B$. bellicosus has also been reported (Martins and Melo, 2010).
In recent decades, the presence of metals such mercury has been noted in the combs and honey pots of bees which inhabit industrial areas (Roman, 2010; Carrero et al., 2013; Pablo et al., 2013). Therefore, the concentration of mercury in honey and pollen is a strong indicator of environmental pollution and an indicator of potential threats to the bee communities (Toporcák et al., 1992; Bogdanov et al., 2007). Mercury can contaminate the raw materials of bee products (nectar and pollen) via the air, water and soil during plant cultivation. Contaminants are transported into the colonies along with the raw materials (Buldini et al., 2001; Bogdanov et al., 2007; Bratu and Georgescu, 2005; Perna et al., 2012; Mbiri et al., 2011 Carrero et al., 2013; Pablo et al., 2013), with serious detrimental effects, as 
mercury exposure can be lethal to bees (Roman, 2010; Tchounwou et al., 2012; Martín et al., 2015).

The impact of trace metals on terrestrial organisms is a growing area of research in Brazil and methods of environmental assessment should be developed in case of environmental disaster such as that which occurred in the state of Minas Gerais recently. The collapse of a dam containing millions of litres of mining waste led to many trace metals including mercury, arsenic, chromium and manganese being released into the Rio Doce river at levels which exceeded safe limits for human consumption (Massarini, 2015). The contamination reached the coast of the state of Espírito Santo, with potential impacts for the wider marine ecosystem (Massarini, 2015). Despite the magnitude of this ecological disaster, few is known about the effect of these metals on the impacted native fauna and flora.

Mercury is not an essential trace metal and is highly toxic for all living beings at any concentration. Environmental levels of mercury have markedly increased in the past few decades (Martín et al., 2015). Besides the well-known neurotoxic effects, cationic trace metals bind to DNA, proteins, enzymes and COO-groups of fatty acids; which can disturb the entire metabolic system of the affected organism. This can cause general metabolic disturbance, endocrine disruption, mutagenesis, cell death and cyto- and genotoxicity (Duruibe et al., 2007; Tchounwou et al., 2012, Abdalla et al., 2015; Abdalla et al., 2018).

Mercury salts such as mercury chloride, ethylmercury, methylmercury and bacterial metabolic residues have strong affinities for organic sulfhydryl thiols. Thiol groups contain sulphur, carbon and hydrogen, which are important constituents of all biological macromolecules and the arrangement of these elements determines the structure and function of such molecules. Mercury can bind to the amino acids of sulfhydryl groups, such as cysteine, glycine, methionine and taurine; forming mercaptides (methyl thiolates). When this reaction occurs in the amino acids of enzymes, the catalytic function can be disrupted or completely eliminated (Jordan and Bhatnagar, 1990; Zimmermann et al., 2013).

The most common reaction of mercury is the interaction with sulphur atoms of cysteine residues to form relatively stable mercury-cysteine complexes. Such complexes can alter the tertiary structure of the protein, with consequent disruption of protein function (Bernhoft, 2012; Caterino et al., 2014). In this way, mercury can lead the inactivation of Heat Shock Proteins (HSPs) which are ubiquitous ATP-dependent molecular chaperones essential for the maintenance of cellular function and homeostasis in almost all living beings (Silva-Zacarin et al., 2006; Pratt et al., 2011). These proteins are classified according to their molecular weight and the most well studied are members of the
HSP70 family (Pratt et al., 2011). Constitutively present in the cytoplasm and nucleus of all eukaryotic cells, HSP70 is involved in ensuring correct protein folding. When eukaryotic cells are under conditions of stress; HSP70 is overexpressed to prevent protein misfolding, mitochondrial damage and nuclear fragmentation (Pratt et al., 2011). In the salivary glands of honeybees under conditions of stress, HSP70 functions as an effective antiapoptotic protein (Silva-Zacarin et al., 2006), leading it to be considered an effective molecular biomarker to study cells under stress in ecotoxicology.

The Hepato-Nephrocitic System (HNS) is a system of fat body and pericardial cells that surround the dorsal vessel, along with haemocytes. The HNS was first described by Abdalla and Domingues (2015) in workers of the neotropical bumblebee B. morio that had been exposed to a "safe" concentration of cadmium. The HNS is involved in immune cell responses via the activity of the haemocytes. Through the pericardial cells, oenocytes and trophocytes the HNS filters, detoxifies and/or alters the bioavailability of xenobiotics for excretion by the Malpighian tubules. Thereby, the survival and mortality rates of bees that are exposed to xenobiotics may not be representative, due to detoxification of the toxins through the HNS (Domingues et al., 2017).

This study aimed to evaluate the morphological, histochemical and HSP70 localisation effects of mercury exposure in the oenocytes, trophocytes and pericardial cells of the HNS (Abdalla and Domingues, 2015) of $B$. morio and $B$. atratus workers. A concentration of mercury was used that is considered environmentally safe $(0.2 \mathrm{ppb})$ according to the Brazilian Environmental Council (CONAMA, 2005).

\section{Materials and Methods}

\section{Bee Collection}

Workers of Bombus morio (Swederus, 1787) and B. atratus (Franklin, 1913) were collected from the remaining fragments of the semi-deciduous forest and Cerrado in the municipality of Sorocaba $\left(23^{\circ} 34^{\prime} 53.1^{\prime \prime} \mathrm{S}\right.$ $47^{\circ} 31^{\prime 29.5 " W ") ~ i n ~ t h e ~ S t a t e ~ o f ~ S a ̃ o ~ P a u l o, ~ B r a z i l . ~ A l l ~}$ workers were collected from flowers of Cassia Linnaeus Sp. (1753), between 9 am and 11:30 am. Bees were collected individually with an entomological net and immediately transferred to a $50 \mathrm{~mL}$ Falcon tube (one bee per tube). All Falcon tubes containing bees were kept in a thermic box in the dark to avoid stress on bees.

\section{Ecotoxicological Procedures}

The workers were kept individually in plastic boxes of $10 \times 14 \times 10 \mathrm{~cm}$ with two feeders glued to the bottom of the box (close to the wall), one for food and one for either fresh water or contaminated solution. The boxes were kept inside an incubator $\left(26^{\circ} \mathrm{C}\right.$, relative humidity [RH] 70\%, in the dark). They were fed ad libitum with a 
solid mixture of honey, dehydrated pollen and organic soy flour. Bioassays were conducted in replicate for both the control and experimental groups ( $n=11$ for each). The control group was offered $2 \mathrm{~mL}$ of water and the experimental group was offered $2 \mathrm{~mL}$ of mercury solution (mercury chloride; Sigma-Aldrich, $99.5+\%$ ) at a concentration of $0.2 \mathrm{ppb}(0.2 \mathrm{ng} \cdot \mathrm{L}-1)$ mercury. After 48 hours of exposure, all bees were sacrificed and the dorsal vessels were dissected directly in fixative solution of $4 \%$ paraformaldehyde. The OECD (2017) guidelines for the testing of chemicals in B. terrestris were consulted.

\section{Morphological and Histochemical Techniques}

The dorsal vessels of the bees were fixed in $4 \%$ paraformaldehyde for $24 \mathrm{~h}$. After fixation, the material was embedded in JB-4 resin (Polysciences, Leica Biosystems Nussloch GmbH, Heidelberg, Germany) according to manufacturer's recommendations, or in paraffin for Acridine Orange and HSP70 immunohistochemistry. Histological sections of $2 \mu \mathrm{m}$ were cut using a Leica microtome (RM2255). The material was stained with haematoxylin and eosin for routine morphological analysis. For fluorescence analysis of HSP70 expression and Acridine Orange analysis, paraffinised histological sections of $6 \mu \mathrm{m}$ were used. For histochemical analysis, the material was stained with Acridine Orange to verify chromatin fragmentation and condensation level. Immunofluorescence was used for the in-situ detection of HSP70 (primary antibody: Goat Serum Normal, secondary antibody: Mouse Anti-Goat IGgFITC, 1/500) according to the manufacturer's protocol (polyclonal antibody protocol; Santa Cruz Biotechnology Inc., USA). Imaging was carried out on a Leica photomicroscope (DM1000). Fluorescence imaging was carried out on a Leica Fluorescence photomicroscope (DM4000) with a B/G/R fluorescence optical system with ultraviolet (BP 465/20), blue (BP 530/30) and green (BP 640/40) excitation bands.

No formal permission or ethical form submission was required for the areas where the bees were collected.

\section{Analysis of Fluorescence Intensity}

The automatic analysis function of the Leica LAS V4.5 software was used to quantify the intensity of the green fluorescence in pericardial and fat body cells for immunofluorescence analysis. Ten panoramic micrographs were analysed (pericardial and fat body cells at magnification of $10 \times$ ) for each individual bee of both the control and experimental groups, resulting in a total of 110 measurements for each group of each species. The variation of the average green intensity was compared within each group (control and experimental) using the Mann-Whitney U test. Tukey's post-hoc multiple comparisons test and one-way analysis of variance (ANOVA) for non-parametric samples (GraphPad Prism
V5.04 software) were carried out for each species in isolation and between the two species.

\section{Results}

\section{Morphology of the Hepato-Nephrocitic System}

Trophocyte nuclei from typical branches of the control groups are shown in Figs. 1A and 2A. Following exposure to mercury, the nuclei of trophocytes of both species were decreased in number and showed a rounded morphology (Figs. 3A and 4A). In the exposed group, trophocytes and oenocytes were identified as collapsed structures; an effect that was especially pronounced in B. atratus (Figs. 3A and $3 B$ ). The oenocytes of the exposed groups lost their characteristic shape (Figs. 3B and 4B) and these cells of $B$. morio exhibited irregular contours and central pyknotic nuclei (Fig. 4B). In B. atratus, the oenocytes formed an indistinguishable cellular mass (Fig. 3B).

The pericardial cells of the control groups were observed to be in stage I for both species; with central nuclei in an epithelioid arrangement, homogeneous cytoplasm and an absence of pinocytosis (Figs. 1C and $2 \mathrm{C}$ ). The pericardial cells of $B$. atratus, following exposure to mercury, presented pyknotic nuclei (Fig. 3C). In mercury-exposed $B$. morio workers, the pericardial cells were turgescent with obvious chromatin fragmentation and condensation, as well as peripherallylocated lumps of chromatin (Fig. 4C).

\section{Histochemistry and In-Situ Localisation of HSP70}

Immunofluorescence analysis using acridine orange staining revealed that the nuclei of oenocytes, trophocytes and pericardial cells of the control group emitted green fluorescence (Figs. 1D-F, 2D-F). Oenocytes of B. morio showed red/orange staining in the cytoplasm (Fig. 2E), the trophocytes only showed green staining (Fig. 2D). Following exposure to mercury, the HNS cell nuclei of both species became red/orange (Figs. 3D-F, 4D-F).

In the control group of both species, HSP70 was localised to both the cytoplasm and nuclei of oenocytes (Fig. $1 \mathrm{H}$ and $2 \mathrm{H}$ ). Examination of the trophocytes revealed that HSP70 was only present in the cytoplasm for both species (Fig. $1 \mathrm{G}$ and $2 \mathrm{G}$ ). The pericardial cells of both species showed weak HSP70 fluorescence (Figs. 1I and 2I). When the exposed group of B. atratus was examined, HSP70 was not detected in the nuclei of trophocytes, oenocytes or pericardial cells (Figs. 3G-I). In the exposed group of $B$. morio, overexpression of HSP70 was observed in the cytoplasm of the trophocytes, oenocytes and pericardial cells (Figs. 4G-I). 

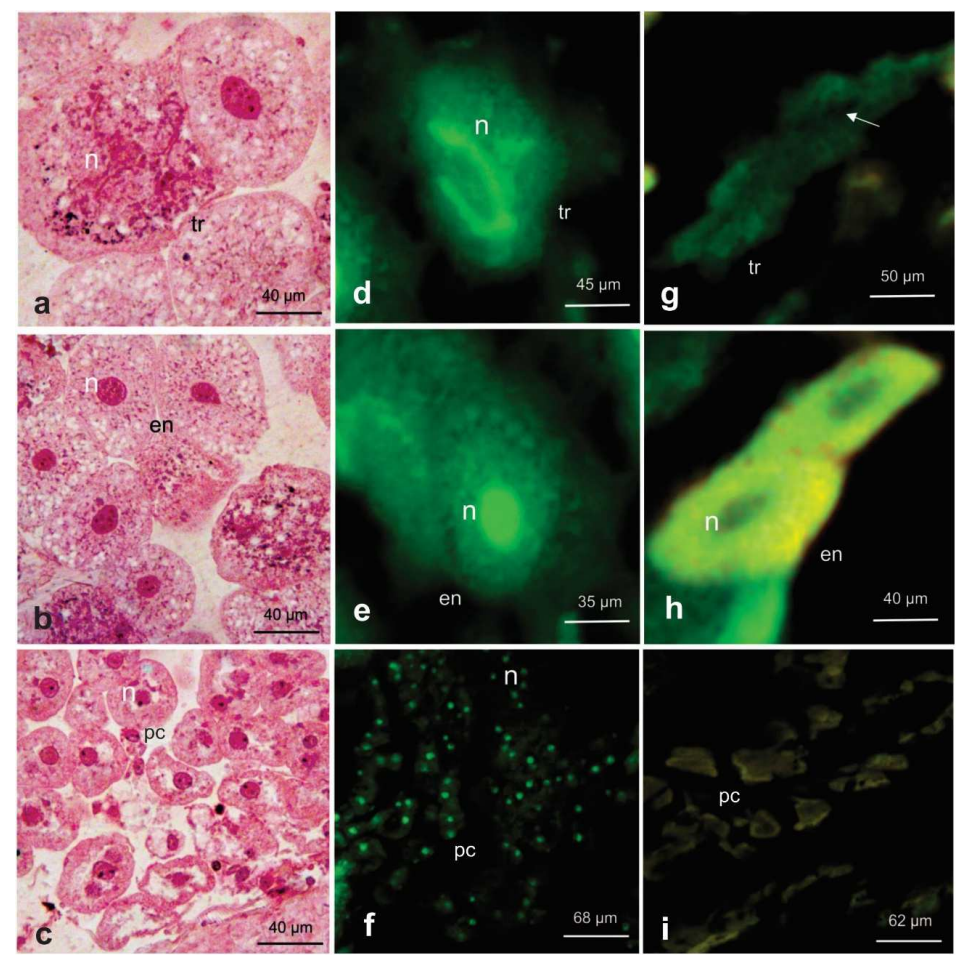

Fig. 1: Morphological and histochemical analysis of trophocytes, oenocytes and pericardial cells of the Bombus atratus control group. (A-C) stained with haematoxylin and eosin; (D-F) stained with Acridine Orange; (G-I) HSP70.

Key: $\mathrm{tr}=$ trophocytes; en = oenocytes, $\mathrm{n}=$ nucleus; $\mathrm{pc}=$ pericardial cells, arrow $=$ level of fluorescence in the nucleus.

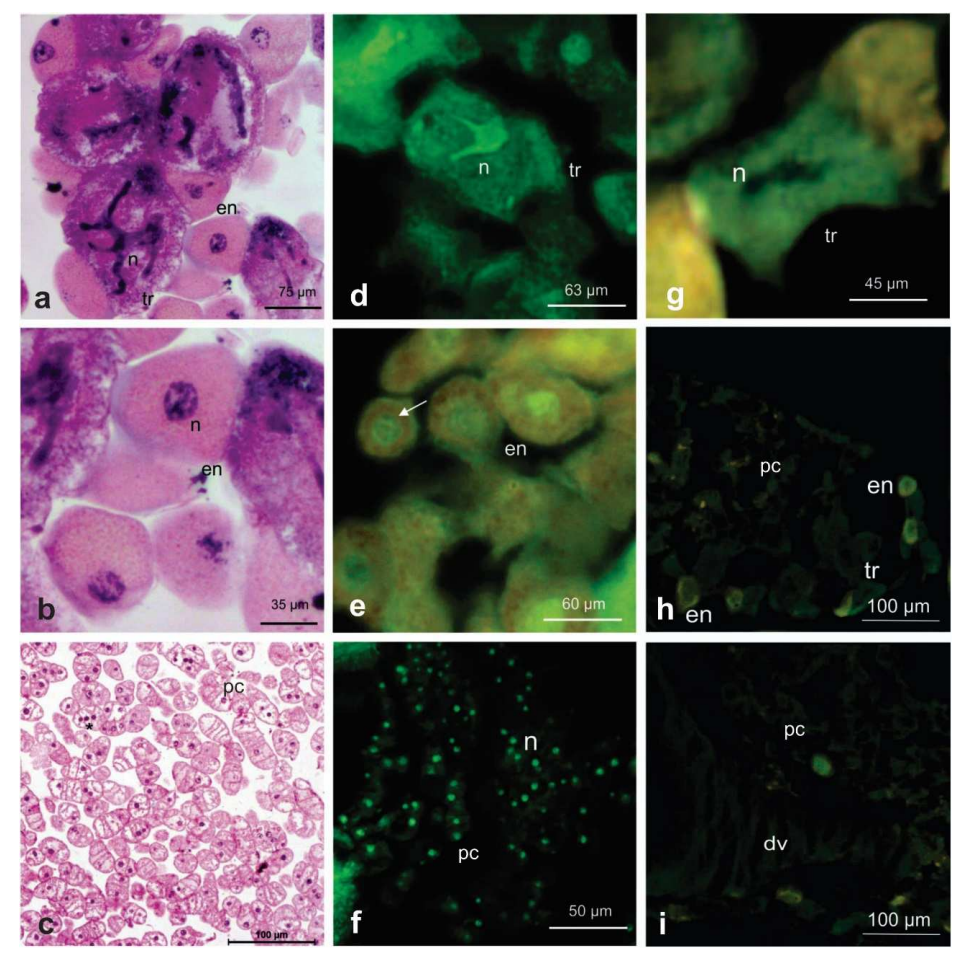

Fig. 2:Morphological and histochemical analysis of trophocytes, oenocytes and pericardial cells of the Bombus morio control group. (A-C) stained with haematoxylin and eosin; (D-F) stained with Acridine Orange; (G-I) HSP70.

Key: $\operatorname{tr}=$ trophocytes; en = oenocytes; $\mathrm{n}=$ nucleus, arrows = RNA; $\mathrm{pc}=$ pericardial cells; $\mathrm{dv}=$ dorsal vessel; arrow $=$ level of fluorescence in the nucleus. 


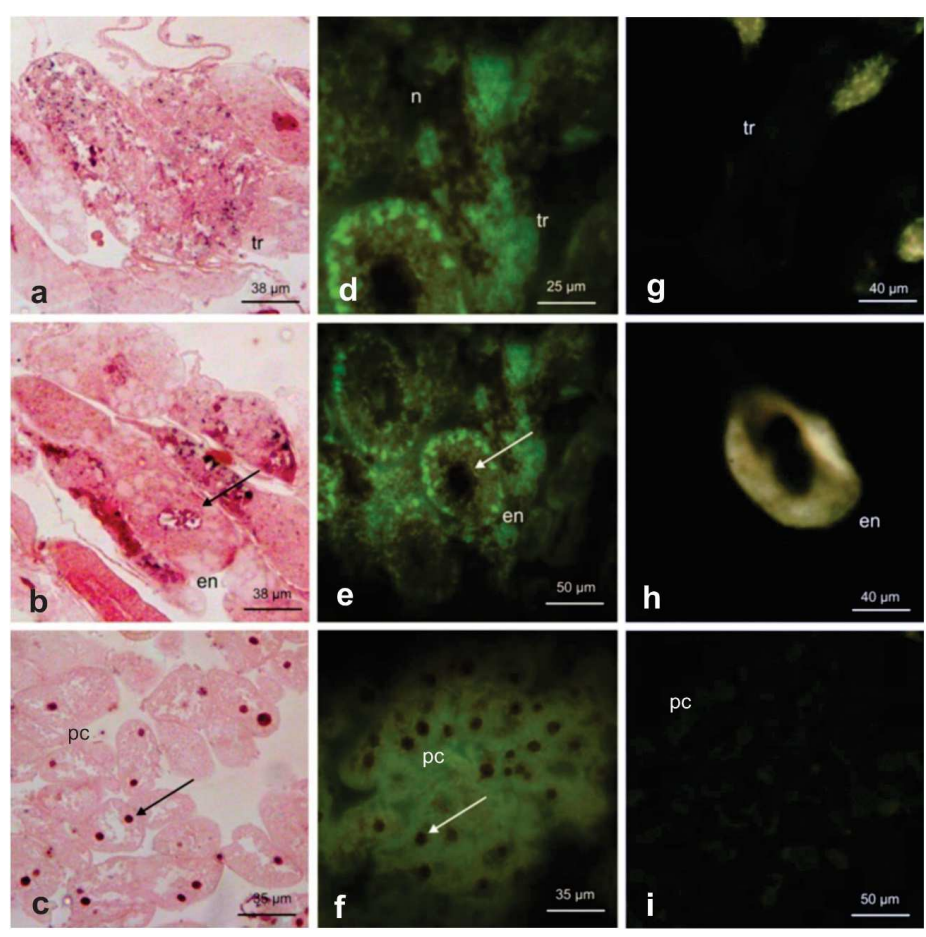

Fig. 3: Morphological and histochemical analysis of trophocytes, oenocytes and pericardial cells of the Bombus atratus exposure group. (A-C) stained with haematoxylin and eosin; (D-F) stained with Acridine Orange; (G-I) HSP70

Key: $\operatorname{tr}=$ trophocytes; en = oenocytes; $n=$ nucleus; arrow = oenocytes and pericardial cell nuclei in (e) and (f), respectively, with chromatin compacted and fragmentated; $\mathrm{pc}=$ pericardial cells; arrow $=$ level of fluorescence in the nucleus.

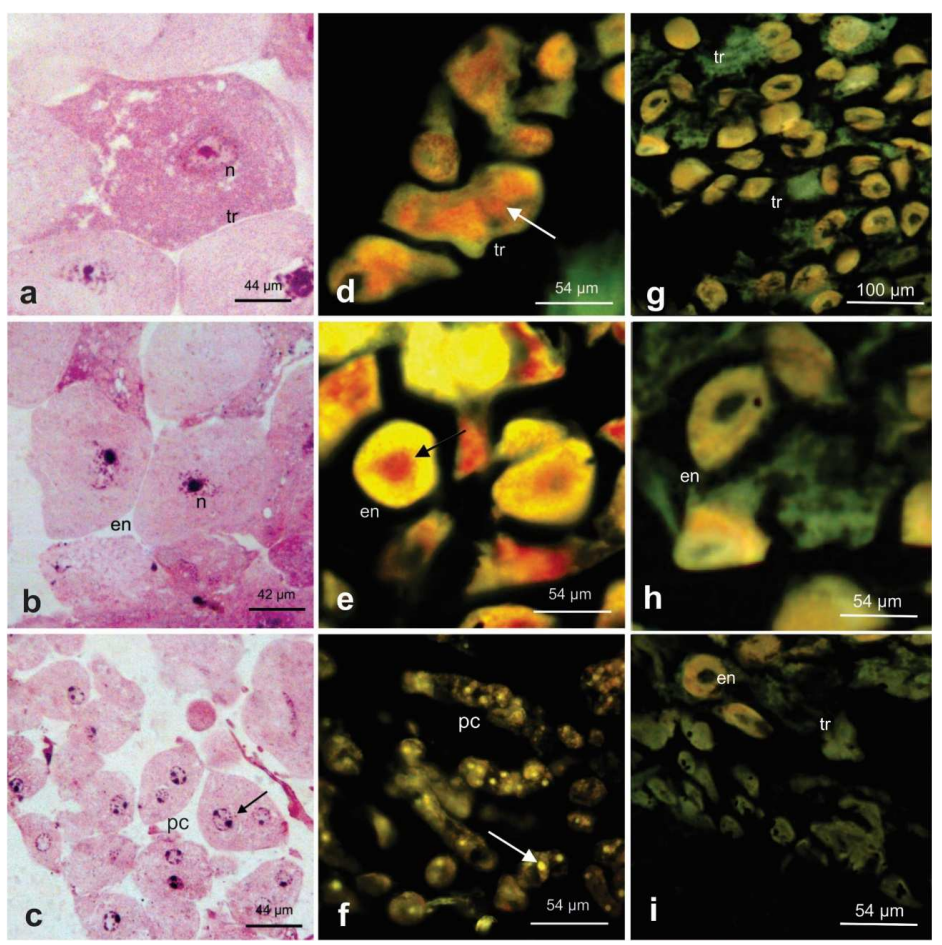

Fig. 4: Morphological and histochemical analysis of trophocytes, oenocytes and pericardial cells of the Bombus morio exposure group. (A-C) stained with haematoxylin and eosin; (D-F) stained with Acridine Orange; (G-I) HSP70.

Key: $\operatorname{tr}=$ trophocytes; en = oenocytes; $\mathrm{n}=$ nucleus; arrow $=$ in (c) pericardial cells with chromatin fragmented and peripheral localisation; arrow = in (d), (e) and (f) fragmentation of the chromatin in the nuclei of the trophocytes, oenocytes and pericardial cells, respectively; $\mathrm{pc}=$ pericardial cells 


\section{Comparison of HSP70 Expression in B. atratus and B. morio}

Fluorescence intensity is a tool which can be used to measure the expression level of fluorochrome-labelled proteins, providing insight that cannot be obtained through examination of the micrographs.

All cells of B. morio showed increased HSP70 expression following exposure to mercury (Fig. 5), whereas expression was reduced in $B$. atratus after exposure (Fig. 6). In B. atratus, the cells exposed to mercury showed significant damage (evident from the morphology and histochemistry results) and HSP70 was found to be under-expressed in the oenocytes and trophocytes $(\mathrm{P}<0.0001)$. However, no significant difference in HSP70 expression was detected between the control and experimental pericardial cells of this species ( $P[0.4664$ ). In addition, the oenocytes of the control groups of both species had the highest levels of HSP70 expression, followed by trophocytes and pericardial cells (Figs. 5 and 6).

In worker bees who were not exposed to mercury, the expression of HSP70 was lower in the oenocytes, trophocytes (40/92) and pericardial cells (40/61) of $B$. morio compared with $B$. atratus (Figs. 5 and 6). The ratios of expression levels between the cell types was significantly different for the control and exposed groups and HSP70 expression increased significantly in all cell types following mercury exposure in B. morio (Fig. 5). However, this trend is almost identical in B. morio; that is, HSP70 expression is $230 \%$ higher in the oenocytes compared with trophocytes in the control group. Following mercury exposure, the fluorescence intensity in the trophocytes did not differ significantly from that of the pericardial cells in either species (Figs. 5 and 6).

\section{Discussion}

The results of the present study indicate that mercury has general systemic effects, as evidenced by the changes observed in all cell types of $B$. atratus and $B$. morio that were analysed (trophocytes, oenocytes and pericardial cells). This suggests that the effects of mercury exposure reach beyond the cells of the nervous system, as HNS cells were found to be in the process of cell death.

Workers of B. morio and B. atratus showed extensive morphological injury of the HNS following $48 \mathrm{~h}$ exposure to $0.2 \mathrm{ppb}$ of mercury. Our morphological analysis provides clear evidence that the fat body cells of both species were damaged, despite the fact that the concentration of mercury that was used is considered safe. The collapse of trophocytes indicated that the exchange machinery between the nucleus and cytoplasm were deactivated, which can lead to disruption of the intermediary metabolism (Roma et al., 2010). The oenocytes also showed significant damage, which could suggest that all of the detoxication enzymes expressed by these cells - such as the P450 enzyme superfamily (Komagata et al., 2010) — may be disabled as a result.

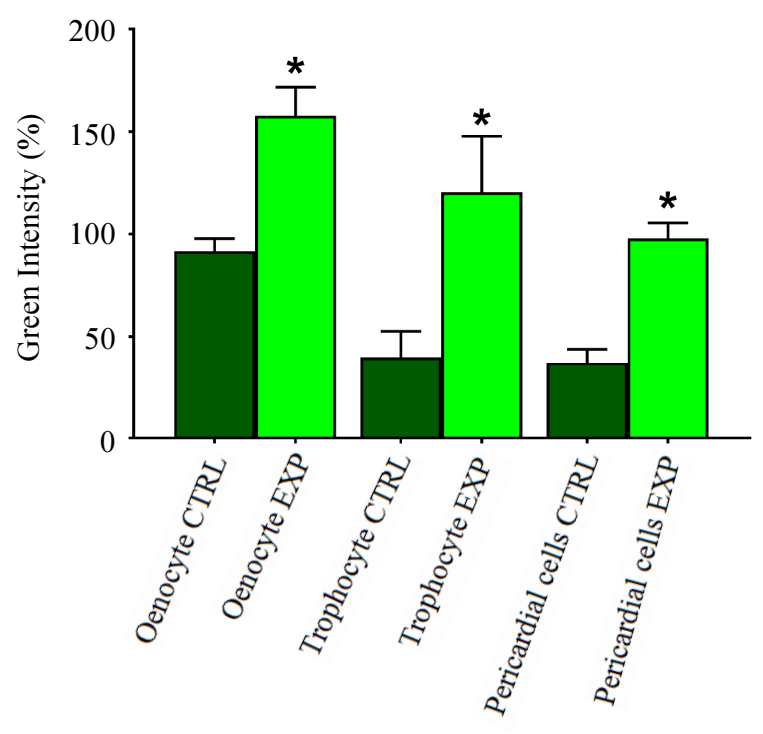

Fig. 5: Histogram of fluorescence intensity of labelled HSP70 in trophocytes, oenocytes and pericardial cells of the control and experimental groups of Bombus morio.

Key: $*=$ HSP70 under-expression in oenocytes and trophocytes for the experimental groups $(\mathrm{P}<0.0001)$, $\mathrm{CTR}=$ control group, $\mathrm{EXP}=$ experimental group.

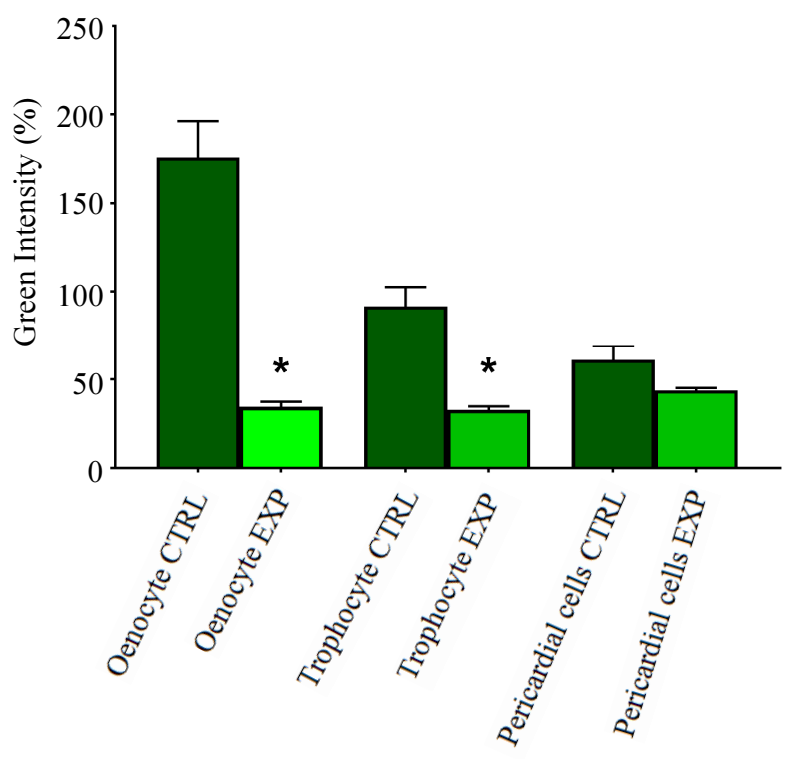

Fig. 6: Histogram of fluorescence intensity of labelled HSP70 in trophocytes, oenocytes and pericardial cells of the control and experimental groups of Bombus atratus Key: $*=$ HSP70 under-expression in oenocytes and trophocytes for the experimental groups $(\mathrm{P}<0.0001)$, $\mathrm{CTR}=$ control group, $\mathrm{EXP}=$ experimental group. 


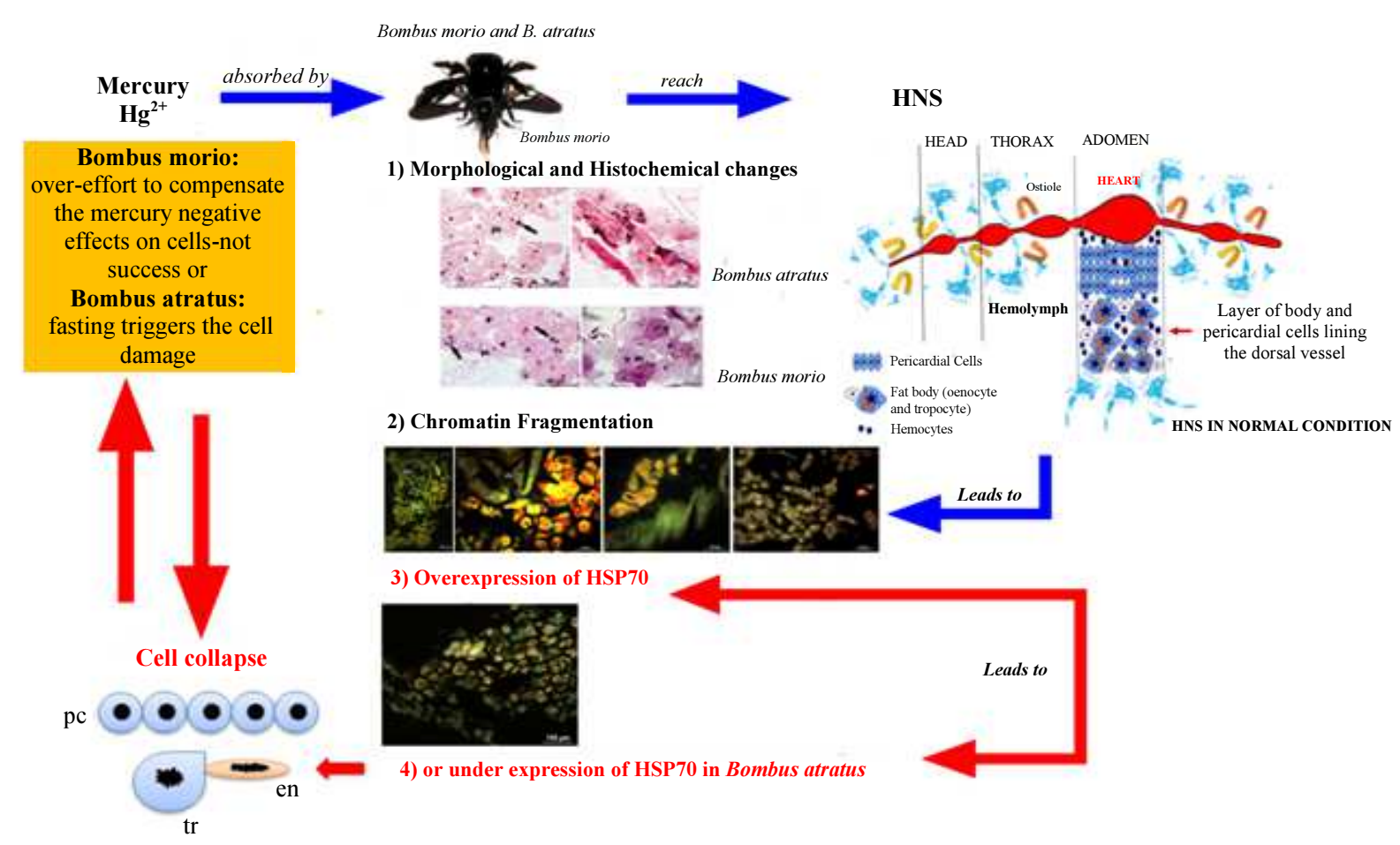

Fig. 7: Infographic summarizing the main the results

The oenocytes of $B$. atratus became an indistinguishable cell mass following mercury exposure and the detoxication system provided by these cells was clearly disabled. The same effects were observed in B. morio following exposure to $1 \mathrm{ppb}$ cadmium (Abdalla and Domingues, 2015). In summary, morphological analysis revealed that the effects of mercury exposure on HNS cells were more dramatic in B. atratus (Fig. 7).

In healthy bees, the pericardial cells are composed of stage I cells, as was observed in the control groups of the present study. When the HNS is activated, the cells increase in size due to increased pinocytosis activity (Mills and King, 1965; Abdalla and Domingues, 2015; Domingues et al., 2017). If the pericardial cells reach stage IV, pinocytosis has reached maximal activity, which may affect the distribution of nutrients and hormones amongst the internal organs of bees due to the associated decrease in haemolymph (Abdalla and Domingues, 2015; Domingues et al., 2017). However, if the pericardial cells are disabled, haemolymph homeostasis is disrupted because xenobiotics in the haemolymph remain in contact with the internal organs for longer (Abdalla and Domingues, 2015; Domingues et al., 2017).

Following exposure to $1 \mathrm{ppb}$ cadmium, pericardial cells have been observed to enter stage IV (Abdalla and Domingues, 2015), whereas exposure to $0.2 \mathrm{ppb}$ mercury resulted in the pericardial cells entering an atypical stage I for both species of the present study. However, $B$. atratus appeared to be more sensitive to mercury than $B$. morio, as the pericardial cells showed signs of more significant damage. The same signs were observed for trophocytes and oenocytes.

The results of acridine orange staining indicated the extent of chromatin fragmentation and cell death in the HNS cells of mercury-exposed B. atratus and B. morio workers. Acridine orange is cell-permeable and nucleic acid selective, with metachromatic properties. When it binds to DNA it emits green fluorescence at $520 \mathrm{~nm}$ and red fluorescence at $650 \mathrm{~nm}$ when it binds to RNA in acidic conditions. The nuclei of non-damaged cells of paraffinised histological preparations which emitted green fluorescence therefore contain intact chromatin, whereas the condensed or fragmented chromatin of apoptotic or necrotic cells is stained orange. The cytoplasm may also be stained green or orange, depending on the absence or presence of cytoplasmic RNA, respectively. This dye is a rapid and inexpensive technique to study nucleic acid metabolism (Ribble et al., 2005); and when used in combination with other dyes, provides a useful tool to investigate cell death and molecular chaperones such as heat shock proteins (HSPs), thus representing a good method to study cells under stress (Silva-Zacarin et al., 2006).

Our results suggested that the oenocytes, trophocytes and pericardial cells of the control group did not suffer chromatin damage. The red/orange cytoplasm of $B$. 
morio oenocytes was due to the presence of abundant cytoplasm RNA and correlated with the function of these cells in producing enzymes related to detoxication (Roma et al., 2010). Oenocytes of B. atratus did not contain cytoplasmic RNA. For both species, the HNS cell nuclei of mercury-exposed bees became red/orange, which confirms that the metal caused chromatin compaction and fragmentation and consequent damage of the cell nuclei, which will hinder cell functions.

Under normal conditions, HSP70 is expressed in constitutive quantities and is an essential molecule for vital biological processes including folding of newly synthesised polypeptides or refolding of misfolded proteins, assembly of multiprotein complexes and transport of proteins across cellular membranes (Pratt et al., 2011). Overexpression of HSP70 suppresses mitochondrial damage and nuclear fragmentation; therefore, the protein functions as a potent antiapoptotic agent (Silva-Zacarin et al., 2006). Under conditions of stress, the synthesis of stress-induced HSP70 can inhibit cell death and therefore increase the survival of cells exposed to a wide range of lethal stimuli (SilvaZacarin et al., 2006; Pratt et al., 2011). Overexpression of HSP70 can also cause activation of HSP70dependent proteins to induce ubiquitin-degradation of abnormal proteins (Pratt et al., 2011). For these reasons, HSP70 is considered to be a molecular biomarker of cellular stress. In the present study, weak HSP70 fluorescence was observed in the cytoplasm or nuclei of trophocytes, oenocytes and pericardial cells of mercury-exposed $B$. atratus bees, which indicates that the cells had lost their ability to express the protein due to mercury-induced cellular damage.

Analysis of fluorescence intensity provided quantitative data on the differences in HSP70 expression patterns between the control and exposed groups of both species. We measured the intensity of green fluorescence of the cytoplasm of oenocytes, trophocytes and pericardial cells of the control and experimental group of both species. Surprising and very informative results were obtained. The HSP70 expression patterns of the control and experimental groups were dramatically different between the species studied. Because the synthesis of stress-induced HSP70 can inhibit cell death and therefore increase the survival of cells exposed to a wide range of lethal stimuli (Pratt et al., 2011), overexpression of the protein in the oenocytes of mercury-exposed $B$. morio indicates that this species is significantly more resistant to mercury compared with $B$. atratus. The morphological and histochemical results support this observation.

To the best of our knowledge, this study is the first to show the expression patterns of HSP70 in these three cell types under normal and experimental conditions.

\section{Conclusion}

The results of this study indicate that exposure to 0.2 ppb mercury severely impacts the fat body and pericardial cells of $B$. atratus and B. morio worker bees, even though it is considered a "safe concentration" by the Brazilian Environmental Council. Exposure impaired the fitness of individuals and may represent a threat for neotropical bee species, which confirms our initial hypothesis. This study also demonstrates that $B$. atratus is more sensitive to mercury exposure than $B$. morio, although the species are phylogenetically close. This study is the first to investigate the expression pattern of HSP70 in the fat body and pericardial cells in neotropical bumblebees under normal and mercury exposure conditions. Finally, we can conclude that the oenocytes are the primary cells involved in the HSP70 protective response.

\section{Acknowledgements}

We thank the São Paulo Research Foundation FAPESP (grant 2017/03653-6), the Brazilian National Council for Scientific and Technological Development CNPq (grant 302812/2016-4) and the Coordination Improvement of Higher Education Personnel (CAPES) for providing financial support for this study.

\section{Funding Information}

This work was supported by the São Paulo Research Foundation FAPESP (grant 2017/03653-6), the Brazilian National Council for Scientific and Technological Development CNPq (grant 302812/2016-4) and the Coordination Improvement of Higher Education Personnel (CAPES).

\section{Author Contributions}

The authors contributed equally to this work.

\section{Conflict of Interest}

The authors declare no conflict of interest.

\section{Ethics}

No formal permission or ethical form submission was required for the areas where the bees were collected.

\section{References}

Abdalla, F.C. and C.E.C. Domingues, 2015. HepatoNephrocitic System: a novel model of biomarkers for analysis of the ecology of stress in environmental biomonitoring. PlosOne, 10: 1-9. DOI: 10.1371/journal.pone.0132349 
Abdalla, F.C., M. Pedrosa, C.E.C. Domingues and P.J Bálsamo, 2018. Effect of cadmium on worker ovary morphology of Bombus morio (Hymenoptera: Bombini). Am. J. Agricultural Biological Sci., 13: 28-37. DOI: 10.3844 /ajabssp.2018.28.37

Bernhoft, R.A., 2012. Mercury toxicity and treatment: A review of the literature. J. Environm. Public Health, 2012: 460-508. DOI: 10.1155/2012/460508

Bogdanov, S., M. Haldimann, W. Luginbuhl and P. Gallmann, 2007. Minerals in honey: environmental, geographical and botanical aspects. J. Apicultural Res., 46: 269-275. DOI: 10.3896/IBRA.1.46.4.11

Bratu, I. and C. Georgescu, 2005. Chemical contamination of bee honey-identifying sensor of the environment pollution. J. Central European Agric., 6: 467-470. DOI: 10.5513/jcea.v6i1.253

Buldini, P.L., S. Cavalli, A. Meovoli and J.L. Sharma, 2001. Ion chromatographic and voltammetric determination of heavy and transition metals in honey. Food Chemistry, 73: 487-495.

DOI: $10.1016 / \mathrm{S} 0308-8146(01) 00132-7$

Carrero, P., C. Rondón, A.R. Saavedra and P. VitOlivier, 2013. A study of $\mathrm{Hg}$ and $\mathrm{Pb}$ content in pothoney (Apidae: Meliponini). In: Stingless bees process honey and pollen in cerumen pots, Vit, P. and D.W. Roubik, (Eds.), Mérida: Faculdad de Farmacia y Bioanálisis, Universidad de Los Andes, ULA, pp: 1-5. ISBN: 978-980-11-1551-9.

Carswell, C., 2015. Climate Change. Bumblebees aren't keeping up with a warming planet. Science, 349: 126-7. DOI: $10.1126 /$ science.349.6244.126

Caterino, M., M. Antonello, A. Balsamo, I.R. Krauss and S. Parisi et al., 2014. Reaction of $\mathrm{Hg}^{2+}$ insertion into cysteine pairs within bovine insulin crystals followed via Raman Spectroscopy. J. Solution Chemistry, 43: 135-143.

DOI: $10.1007 / \mathrm{s} 10953-013-0066-y$

CONAMA, 2005. Resolução Conama n ${ }^{\circ}$ 357, de 17 de março de 2005. http://www2.mma.gov.br/port/conama/legiabre.cfm? codlegi $=459$

Domingues, C.E.C., F.C. Abdalla, P.J. Bálsamo, B.V.R. Pereira and M.A. Hausen et al., 2017. Thiamethoxam and picoxistrobin reduce the survival and overload the Hepato-Nephrocitic System of the africanized honeybee. Chemosphere, 186: 994-1005. DOI: $10.1016 /$ j.chemosphere.2017.07.133

Duruibe, J.O., M.O.C. Ogwuegbu and J.N. Egwurugwu, 2007. Heavy metal pollution and human biotoxic effects. Int. J. Physical Sci., 2: 112-118.

Gallai, N., J. Salles, J. Settele and B.E. Vaissière, 2009. Economic valuation of the vulnerability of world agriculture confronted with pollinator decline. Ecological Economics, 68: 810-821.

DOI: 10.1016/j.ecolecon.2008.06.014
Goulson, D., E. Nicholls, C. Botías and E.L. Rotheray, 2015. Bee declines driven by combined stress from parasites, pesticides and lack of flowers. Science, 347: 1255957-1-1255957-9.

DOI: $10.1126 /$ science. 1255957

Grixti, J.C., L.T. Wong, S.A. Cameron and C. Favret, 2009. Decline of bumble bees (Bombus) in the North American Midwest. Biological Conservation, 142: 75-84. DOI: 10.1016/j.biocon.2008.09.027

Jordan, S.A. and M.K. Bhatnagar, 1990. Hepatic enzyme activity after combined administration of methilmercury, lead and cadmium in the pekin duck. Bulletin of Environmental Contamination Toxicol., 44: 623-628. PMID: 2157510

Komagata, O., S. Kasai and T. Tomita, 2010. Overexpression of cytochrome $\mathrm{P} 450$ genes in pyrethroid-resistant Culex quinquefasciatus. Insect Biochemistry Molecular Biology, 40: 146-152. DOI: 10.1016/j.ibmb.2010.01.006

Martín, J.A.R., C.D. Arana, J.J. Ramos-Miras, C. Gil and R. Boluda, 2015. Impact of 70 years urban growth associated with heavy metal. Environmental Pollution, 196: 156-163. DOI: $10.1016 / \mathrm{j}$.envpol.2014.10.014

Martins, A.C. and G.A.R. Melo, 2010. Has the bumblebee Bombus bellicosus gone extinct in the northern portion of its distribution range in Brazil? J. Insect Conservation, 14: 207-210. DOI: $10.1007 / \mathrm{s} 10841-009-9237-y$

Massarini, L., 2015. Brazilian mine disaster releases dangerous metals, Mariana, Brazil.

Mbiri, A., A. Onditi, N. Oyaro and E. Murago, 2011. Determination of essential and heavy metals in Kenyan honey by atomic absorption and emission spectroscopy. Jomo Kenyatta University of Agriculture and Technology, Nairobi, Kenya.

Mills, R.P. and R.C. King, 1965. The pericardial cells of Drosophila melanogaster. Quarterly J. Microscopical Sci., 106: 261-268. PMID: 5865262

OECD, 2017. Test No. 247: Bumblebee, Acute Oral Toxicity Test. OECD Guidelines for the Testing of Chemicals.

Pablo, C., C. Rondón, A.R. Saavedra and P. Vitt., 2013. A study of $\mathrm{Hg}$ and $\mathrm{Pb}$ content in pot-honey (Apidae: Meliponini). In: Stingless Bess Process Honey And Pollen In Cerumen Pots, Vit, P. and D.W. Roubik, (Eds.), Faculdad de Farmacia y Bioanálisis, Universidad de Los Andes, Mérida, Venezuela, pp: 1-5. ISBN: 978-980-11-1551-9.

Perna, A., A. Simonetti, I. Intaglietta, A. Sofo and E. Gambacorta. 2012. Metal content of southern Italy honey of different botanical origins and its correlation with polyphenol content and antioxidant activity. Int. J. Food Sci. Technol., 47: 1909-1917. DOI: $10.1111 /$ j.1365-2621.2012.03050.x 
Pratt, W.B., Y. Morishima, H.M. Peng and O. Yoichi, 2011. Role of the Hsp90/Hps70-based chaperone machinery in making triage decisions when proteins undergo oxidative and toxic damage. Experimental Biology $\quad$ Medicine, 235: 278-289. DOI: 10.1258/ebm.2009.00925

Rhoades, P.R., J.B. Koch, L.P. Waits, J.P. Strange and S.D. Eigenbrode, 2016. Evidence for Bombus occidentalis (Hymenoptera: Apidae) populations in the olympic peninsula, the Palouse Prairie and forests of Northern Idaho. J. Insect Sci., 16: 1-5. DOI: $10.1093 /$ jisesa/iev155

Ribble, D., N.B. Goldstein, D.A. Norris and Y.G. Shellman, 2005. A simple technique for quantifying apoptosis in 96-well plates. BMC Biotechnology, 5: 12. DOI: $10.1186 / 1472-6750-5-12$

Roma, G.C., O.C. Bueno and M.I. Camargo-Mathias, 2010. Morphophysiological analysis of the insect fat body: A review. Micron, 41: 395-401. DOI: 10.1016/j.micron.2009.12.007

Roman, A., 2010. Levels of copper, selenium, lead and cadmium in forager bees. J. Environ. Studies Sciences, 19: 663-669.

Silva-Zacarin, E.C.M., A. Gregorc and R.L.M. Silva-deMoraes, 2006. In situ localization of heat-shock proteins and cell death labelling in the salivary gland of acaricide-treated honeybee larvae. Apidologie, 37: 507-516. DOI: org/10.1051/apido:2006030

Tchounwou, P.B., C.G. Yedjou, A.K. Patlolla and D.J. Sutton, 2012. Heavy metals toxicity and the environment. National Institutes Health, 101: 133-164. DOI: $10.1007 / 978-3-7643-8340-4 \_6$

Toporcák, J., J. Legáth and J. Kulková, 1992. Levels of mercury in samples of bees and honey from areas with and without industrial contamination. Veterinární Medicína Czech, 37: 405-412. 1992. PMID: 1413402

U.S. Fish and Wildlife Service, 2017. Rusty patched bumble bee Bombus affinis.
Woodcock, B.A., N.J.B. Isaac, J.M. Bullock, D.B. Roy and D.G. Garthwaite et al., 2016. Impacts of neonicotinoid use on long-term population changes in wild bees in England. Nature Communications. DOI: $10.1038 /$ ncomms 12459

Zimmermann, L.T., D.B. Santos, A.A. Naime, R.B. Leal and J.G. Dórea et al., 2013. Comparative study on methyl-and ethylmercury-induced toxicity in C6 glioma cells and the potential role of LAT-1 in mediating mercurial-thiol complexes uptake. Neurotoxicology, 38: 1-8.

DOI: 10.1016/j.neuro.2013.05.015

\section{Abbreviation and Units}

HNS: Hepato-Nephrocitic System

$\mathrm{Hg}$ : mercury

ppb: parts per billion

NADPH: Dihydronicotinamide-adenine dinucleotide phosphate

RH: relative humidity

$\mathrm{mL}$ : milliliter

ng L-1: nanogram per liter

$\mu \mathrm{m}$ : micrometer

h: hour

P450: cytochrome P450

nm: nanometer

RNA: ribonucleic acid

HSP: heat shock proteins

CONAMA: National Council for the Environment

tr: trophocytes

en: oenocytes

n: nucleus

pc: pericardial cells

dv: dorsal vessel

CTR: control group

EXP: experimental group 